\title{
Article \\ Diabetic Retinopathy and Skin Tissue Advanced Glycation End Products Are Biomarkers of Cardiovascular Events in Type 2 Diabetic Patients
}

\author{
Alejandra Planas ${ }^{1,2}$, Olga Simó-Servat ${ }^{1,2}$, Cristina Hernández ${ }^{1,2} \mathbb{D}$, Ángel Ortiz-Zúñiga ${ }^{1,2} \mathbb{D}$, \\ Joan Ramón Marsal ${ }^{3,4}$, José R. Herance ${ }^{5,6}$, Ignacio Ferreira-González ${ }^{3,4}$ and Rafael Simó ${ }^{1,2, * \text { (D) }}$
}

Citation: Planas, A.; Simó-Servat, O. Hernández, C.; Ortiz-Zúñiga, Á.; Marsal, J.R.; Herance, J.R.;

Ferreira-González, I.; Simó, R. Diabetic Retinopathy and Skin Tissue Advanced Glycation End Products Are Biomarkers of Cardiovascular Events in Type 2 Diabetic Patients. J. Pers. Med. 2021, 11, 1344. https:// doi.org/10.3390/jpm11121344

Academic Editor:

Agata Bielecka-Dabrowa

Received: 18 November 2021

Accepted: 5 December 2021

Published: 10 December 2021

Publisher's Note: MDPI stays neutral with regard to jurisdictional claims in published maps and institutional affiliations.

Copyright: (c) 2021 by the authors. Licensee MDPI, Basel, Switzerland. This article is an open access article distributed under the terms and conditions of the Creative Commons Attribution (CC BY) license (https:// creativecommons.org/licenses/by/ $4.0 /)$.
1 Diabetes and Metabolism Research Unit, Vall d'Hebron Research Institute (VHIR), Vall d'Hebron University Hospital, Autonomous University of Barcelona, 08035 Barcelona, Spain; a.planas@vhebron.net (A.P.); olga.simo@vhir.org (O.S.-S.); cristina.hernandez@vhir.org (C.H.); a.ortiz@vhebron.net (Á.O.-Z.)

2 CIBER de Diabetes y Enfermedades Metabólicas Asociadas (CIBERDEM), Spanish Institute of Health (ISCIII), 28029 Madrid, Spain

3 Cardiology Department, Vall d'Hebron University Hospital and Research Institute, Autonomous University of Barcelona, 08035 Barcelona, Spain; joseprmarsal@yahoo.es (J.R.M.); iferreir@vhebron.net (I.F.-G.)

4 CIBER en Epidemiología y Salud Pública (CIBERESP), Spanish Institute of Health (ISCIII), 28029 Madrid, Spain

5 Medical Molecular Imaging Research Group, Vall d'Hebron Research Institute (VHIR), Nuclear Medicine Department, Vall d'Hebron University Hospital, CIBBIM-Nanomedicine, Autonomous University Barcelona, 08035 Barcelona, Spain; jherance@vhebron.net

6 CIBERBBN, Spanish Institute of Health (ISCIII), 28029 Madrid, Spain

* Correspondence: rafael.simo@vhir.org; Tel.: +34-9-3489-4172

\begin{abstract}
Risk of cardiovascular events is not homogeneous in subjects with type 2 diabetes; therefore, its early identification remains a challenge to be met. The aim of this study is to evaluate whether the presence of diabetic retinopathy and accumulation of advanced glycation end-products in subcutaneous tissue can help identify patients at high risk of cardiovascular events. For this purpose, we conducted a prospective study (mean follow-up: 4.35 years) comprising 200 subjects with type 2 diabetes with no history of clinical cardiovascular disease and 60 non-diabetic controls matched by age and sex. The primary outcome was defined as the composite of myocardial infarction, coronary revascularization, stroke, lower limb amputation or cardiovascular death. The Cox proportional hazard multiple regression analysis was used to determine the independent predictors of cardiovascular events. The patients with type 2 diabetes had significantly more cardiovascular events than the non-diabetic subjects. Apart from the classic factors such as age, sex and coronary artery calcium score, we observed that the diabetic retinopathy and advanced glycation end-products in subcutaneous tissue were independent predictors of cardiovascular events. We conclude that the diabetic retinopathy and advanced glycation end-products in subcutaneous tissue could be useful biomarkers for selecting type 2 diabetic patients in whom the screening for cardiovascular disease should be prioritized, thereby creating more personalized and cost-effective medicine.
\end{abstract}

Keywords: cardiovascular disease; advanced glycation end-products; diabetic retinopathy; cardiovascular disease biomarkers; type 2 diabetes; diabetic complications

\section{Introduction}

Type 2 diabetes confers a substantial burden of macrovascular disease, with twoto four-fold increased risk of any cardiovascular event in comparison with non-diabetic patients [1]. Although type 2 diabetes is an independent risk factor for cardiovascular disease (CVD), not all patients with diabetes appear to be at equal risk. In fact, a high percentage of these patients will never experience vascular complications [2]. Therefore, 
early identification of diabetic patients at risk of developing CVD remains a challenge to be met $[3,4]$.

It is well known that chronic hyperglycemia is related to cardiovascular (CV) complications of diabetes. However, the exaggerated risk for CVD in this population is not explained fully by conventional risk factors such obesity, hyperglycemia, dyslipidemia and hypertension, and, in fact, a substantial proportion of this risk remains unexplained [3,4]. Therefore, specific diabetes-related risk factors should be involved in the excess risk for CVD, and the tissue accumulation of advanced glycation end-products (AGEs) could be one of them.

AGEs accumulate in the body during aging, and this process is accelerated by chronic hyperglycemia and oxidative stress [5], two conditions commonly present in type 2 diabetes. Therefore, the formation and accumulation of AGEs are accelerated by the diabetic milieu and contribute to vascular dysfunction and the accelerated development of atherosclerotic processes [6,7].

In recent years, a simple and non-invasive method for AGEs assessment through skin autofluorescence (SAF) has been validated [8] and related to the presence of micro- and macroangiopathy in individuals with type 2 diabetes [9]. In this regard, we previously reported that SAF was a good predictor of calcium score (CACs) > $400 \mathrm{AU}$, a reliable marker of coronary atherosclerosis [10].

Emerging data indicate that the presence of diabetic microvascular complications increases the risk of CVD [11,12]. In particular, diabetic retinopathy (DR) has been linked with an increase in risk for all-cause and cardiovascular mortality in patients with diabetes [12-14]. In this regard, it should be noted that diabetic-induced microvascular abnormalities that occur in the retina may also arise in other vascular beds, such as myocardial microcirculation $[15,16]$. However, DR is often missing as a risk factor in studies addressed to evaluate CVD.

On this basis, the aim of this study is to evaluate whether the presence of diabetic retinopathy and accumulation of advanced glycation end-products (AGEs) in subcutaneous tissue can help to identify patients with type 2 diabetes at high risk of developing $\mathrm{CV}$ events and allow us to develop more personalized and cost-effective medicine.

\section{Materials and Methods}

\subsection{Study Design and Subjects}

This was a prospective case-control study comprising 200 subjects with type 2 diabetes and 60 non-diabetic controls matched by age and sex, all of them with no history of clinical CVD. The included subjects were enrolled in the PRECISED study (ClinicalTrial.gov accessed on 16 November 2021, NCT02248311).

All subjects enrolled met the following criteria: (a) type 2 diabetes diagnosed at least one year prior to the day of screening; (b) age from 50 to 79 years; (c) no history of vascular event; (d) no contraindication for the performance of CT scan or SAF assessment; and (e) no concomitant disease associated with a short life expectancy.

All included subjects were selected from the Outpatient Diabetic Clinic of Vall d'Hebron University Hospital and primary healthcare centers within its catchment area (North Barcelona). The recruitment period began on September 2014 and finished on June 2017. Of the 200 patients with type 2 diabetes, 13 withdrew consent, and the same occurred in 3 out 60 from the control group. Consequently, 187 subjects with type 2 diabetes and 57 non-diabetic controls were followed until December 2020.

The study was conducted according to the Declaration of Helsinki and was approved by the local ethics committee. All subjects provided written informed consent before study entry. 


\subsection{Data Collection and Laboratory Tests}

Basal features of the subjects and classical cardiovascular risk factors (age, sex, ethnicity, current smoking, body mass index, systolic and diastolic blood pressure, clinical characteristic of diabetes disease and associated comorbidities) were collected during the first visit. In addition, a fasting venous blood sample was obtained from each recruited patient. Please see details in Appendix A.

\subsection{Fundus Eye Examination}

DR was evaluated by experienced ophthalmologists in mydriasis using slit-lamp biomicroscopy and retinography with the same camera (Topcon-DRI-OCTTRITON). The examiners classified DR according to the International Clinical Diabetic Retinopathy Disease Severity Scale [17]: (1) no apparent retinopathy, (2) mild non-proliferative retinopathy (NPDR), (3) moderate NPDR, (4) severe NPDR and (5) proliferative diabetic retinopathy (PDR).

\subsection{Measurement of Skin Autofluorescence}

SAF was measured using the AGE ReaderTM (DiagnOptics TechnologiesBV, Groningen, The Netherlands), a non-invasive desktop device. The AGE ReaderTM detects the characteristic fluorescence of some AGEs and was used to estimate the level of AGEs in the skin, and optical details of this non-invasive method have been described more extensively elsewhere [8] and are summarized in Appendix A.

\subsection{CT-CAC Scanning}

First, the patient was prepared with beta blockers to decrease the heart rate, and nitroglycerin for vasodilatation if needed. Then, an ECG-synchronized prospective contrastenhanced coronary CT was performed with SiemensBiograph mCT 64 s equipment (Siemens Healthcare $\mathrm{GmbH}$, Erlangen, Germany). Automatic coronary vessel extraction of all coronary vessels with visual analysis of coronary stenosis was performed by researchers blind to the patient's condition with "Syngo.Via" cardiac CT software, as described elsewhere [18]. The subjects were divided into two groups according their CACs: CAC $<400 \mathrm{AU}$ and CAC $>400$ AU. A value of CACs $\geq 400$ AU was considered as "high coronary risk".

\subsection{Outcome}

The primary outcome was the time to the first CV event. We defined a CV event as a composite of myocardial infarction, coronary revascularization, stroke, lower limb amputation or $\mathrm{CV}$ death.

\subsection{Statistical Analysis}

Differences among groups were analyzed using Student's $t$-test for quantitative variables with a normal distribution and Pearson's chi-squared test for categorical variables. We calculated event-free survival according to the Kaplan-Meier method.

The Cox proportional hazard multiple regression analysis was used to determine independent predictors of CV events. Statistical analyses were performed with Stata statistical package 15. Significance was accepted at the level of $p<0.05$ for all analyses.

\section{Results}

\subsection{Basal Characteristics of the Sample}

The clinical characteristics and main laboratory findings of both groups (type 2 diabetes and controls), and the specific characteristics of subjects with type 2 diabetes, are shown in Table 1. We did not find any significant differences between groups regarding age, gender, ethnicity, smoking habit or family history of CVD. The specific characteristics of subjects with type 2 diabetes are shown in Appendix B (Table A1). 
Table 1. Characteristics of subjects with type 2 diabetes and non-diabetic control subjects.

\begin{tabular}{|c|c|c|c|}
\hline & $\begin{array}{c}\text { Type } 2 \text { Diabetes } \\
(n=187)\end{array}$ & $\begin{array}{c}\text { Control Group } \\
(n=57)\end{array}$ & $p$ \\
\hline Sex (woman) $(n, \%)$ & $108(57.75 \%)$ & $37(64.91 \%)$ & 0.33 \\
\hline Ethnicity (Caucasian $n, \%$ ) & $179(95.72 \%)$ & $56(98.25 \%)$ & 0.65 \\
\hline Age (years) & $65.63 \pm 6.52$ & $66.01 \pm 6.63$ & 0.85 \\
\hline $\operatorname{BMI}\left(\mathrm{kg} / \mathrm{m}^{2}\right)$ & $30.23 \pm 4.89$ & $26.83 \pm 3.11$ & $<0.001$ \\
\hline Waist circumference $(\mathrm{cm})$ & $103.9 \pm 13.53$ & $91.2 \pm 13.92$ & $<0.001$ \\
\hline \multicolumn{4}{|l|}{ Smoking } \\
\hline $\operatorname{No}(n, \%)$ & $99(48.13 \%)$ & $34(59.65 \%)$ & 0.59 \\
\hline Current Smoker $(n, \%)$ & $25(13.36 \%)$ & $7(12.3 \%)$ & \\
\hline Ex-smoker $(n, \%)$ & $62(33.15 \%)$ & $15(26.32 \%)$ & \\
\hline CV family history $(n, \%)$ & $22(11.76 \%)$ & $8(14.04 \%)$ & 0.65 \\
\hline Hypertension $(n, \%)$ & $135(71.19 \%)$ & $28(49.12 \%)$ & 0.001 \\
\hline Use of ACEi/ARB $(n, \%)$ & $118(63.1 \%)$ & $18(31.58 \%)$ & $<0.001$ \\
\hline Dyslipidemia $(n, \%)$ & $149(79.67 \%)$ & $25(43.86 \%)$ & $<0.001$ \\
\hline Use of statins $(n, \%)$ & $133(71.51 \%)$ & $19(31.67 \%)$ & $<0.001$ \\
\hline Use of ezetimibe $(n, \%)$ & $10(5.38 \%)$ & 0 & 0.074 \\
\hline Total cholesterol (mmol/L) & $4.78 \pm 0.92$ & $5.57 \pm 0.91$ & $<0.001$ \\
\hline HDL cholesterol (mmol/L) & $1.28 \pm 0.32$ & $1.28 \pm 0.29$ & $<0.001$ \\
\hline LDL cholesterol(mmol/L) & $2.72 \pm 0.78$ & $3.43 \pm 0.81 .14$ & $<0.001$ \\
\hline Triglycerides (mmol/L) & 1.73 [0.50-5.67] & $1.24[0.46-5.27]$ & 0.012 \\
\hline $\mathrm{HbA1c}(\mathrm{mmol} / \mathrm{mol})$ & $56.33 \pm 9.01$ & $42.02 \pm 3$ & $<0.001$ \\
\hline $\mathrm{HbA1c}(\%)$ & $7.44 \pm 1.19$ & $5.55 \pm 0.31$ & $<0.001$ \\
\hline Creatinine (mmol/L) & $0.725 \pm 0.021$ & $0.067 \pm 0.0 .017$ & 0.075 \\
\hline GFR $\mathrm{mL} / \mathrm{min}$ & $81.76 \pm 16.00$ & $85.57 \pm 10.88$ & 0.09 \\
\hline AST (UI/L) & $25.51 \pm 15.71$ & $23.48 \pm 5.73$ & 0.34 \\
\hline ALT (UI/L) & $25.94 \pm 16.88$ & $21.12 \pm 10.55$ & 0.043 \\
\hline GGT (UI/L) & $44.46 \pm 71.82$ & $31.04 \pm 29.77$ & 0.17 \\
\hline Skin AF (AU) & $2.68 \pm 0.65$ & $2.41 \pm 0.60$ & 0.001 \\
\hline Log CACs & $2.11 \pm 0.81$ & $1.59 \pm 0.72$ & 0.002 \\
\hline $\mathrm{CCsA} \geq 400 \mathrm{AU}(n, \%)$ & $41(21.93 \%)$ & 0 & $<0.001$ \\
\hline
\end{tabular}

\subsection{Follow-Up}

187 subjects with type 2 diabetes and 57 non-diabetic controls were followed until December 2020. After a follow-up of $4.35 \pm 1.43$ years, a total of $24 \mathrm{CV}$ events were registered, $23 \mathrm{CV}$ events (12.3\%) in type 2 diabetes group, and $1(1.75 \%)$ in the non-diabetic control group. The Kaplan-Meier analysis shows vascular event-free survival regarding the groups $(p=0.031)$, (Figure 1 ).

In the type 2 diabetes cohort, we found an incidence rate of $\mathrm{CV}$ events of 28.2 per 1000 person years. The main basal clinical characteristics of patients with type 2 diabetes according to the presence of the primary outcome (the first vascular event) are shown in Table 2. 
Table 2. Clinical characteristics of patients with type 2 diabetes according to presence of primary outcome (first cardiovascular event).

\begin{tabular}{|c|c|c|c|}
\hline & CV Event $+(n=23)$ & CV Event $-(n=164)$ & $p$ \\
\hline Follow up $(y)$ & $5.09 \pm 1.20$ & $5.21 \pm 0.95$ & 0.564 \\
\hline Sex (woman) $(n, \%)$ & $8(34.7 \%)$ & $100(60.9 \%)$ & 0.017 \\
\hline Age (years) & $68.61 \pm 6.04$ & $65.22 \pm 6.49$ & 0.019 \\
\hline $\operatorname{BMI}\left(\mathrm{kg} / \mathrm{m}^{2}\right)$ & $30.18 \pm 4.19$ & $30.23 \pm 4.99$ & 0.961 \\
\hline Diabetes duration (years) & $17.69 \pm 9.44$ & $14.08 \pm 9.34$ & 0.084 \\
\hline Waist circumference $(\mathrm{cm})$ & $105.6 \pm 11.89$ & $103.69 \pm 13.7$ & 0.552 \\
\hline \multicolumn{3}{|l|}{ Smoking } & \multirow{4}{*}{0.943} \\
\hline $\operatorname{No}(n, \%)$ & $11(47.8 \%)$ & $88(53.65 \%)$ & \\
\hline Current smoker $(n, \%)$ & $03(13.04 \%)$ & $22(13.41 \%)$ & \\
\hline Ex-smoker $(n, \%)$ & $08(34.37 \%)$ & $55(33.53 \%)$ & \\
\hline Hypertension $(n, \%)$ & $17(73.9 \%)$ & $118(71.9 \%)$ & 0.844 \\
\hline Dyslipidemia $(n, \%)$ & $16(69.76)$ & $133(81.1 \%)$ & 0.198 \\
\hline Insulin treatment $(n, \%)$ & $17(73.9 \%)$ & $91(54.48 \%)$ & 0.198 \\
\hline Fast plasma glucose (mmol/L) & $7.99 \pm 2.43$ & $8.73 \pm 2.79$ & 0.232 \\
\hline $\mathrm{HbA1c}(\mathrm{mmol} / \mathrm{mol})$ & $58.45 \pm 8.10$ & $56.1 \pm 9.08$ & 0.234 \\
\hline $\mathrm{HbA1c}(\%)$ & $7.72 \pm 1.07$ & $7.41 \pm 1.20$ & 0.234 \\
\hline Total cholesterol (mmol/L) & $4.69 \pm 0.66$ & $4.78 \pm 0.95$ & 0.682 \\
\hline HDL cholesterol (mmol/L) & $1.33 \pm 0.38$ & $1.27 \pm 0.30$ & 0.399 \\
\hline LDL cholesterol (mmol/L) & $2.73 \pm 0.47$ & $2.71 \pm 0.82$ & 0.906 \\
\hline Triglycerides (mmol/L) & $1.39[0.51-2.5]$ & $1.53[0.6-5.7]$ & 0.046 \\
\hline Homocysteine $(\mu \mathrm{mol} / \mathrm{L})$ & $12.5[8.1-17.4]$ & $11.3[5.8-127]$ & 0.765 \\
\hline Lipoprotein (a) (mg/dL) & $7.21[1-91.2]$ & $8.45[1-162.9]$ & 0.745 \\
\hline GFR (mL/min) & $86.5 \pm 11.18$ & $81.12 \pm 16.46$ & 0.285 \\
\hline Creatinine (mmol/L) & $0.068 \pm 0.01$ & $0.0734 \pm 0.02$ & 0.278 \\
\hline \multicolumn{3}{|l|}{ Albumin/creatinine ratio } & \multirow{4}{*}{0.06} \\
\hline$<3.39 \mathrm{mg} / \mathrm{mmol}(n, \%)$ & $9(40.9 \%)$ & $111(68.5 \%)$ & \\
\hline $3.39-33.9 \mathrm{mg} / \mathrm{mmol}(n, \%)$ & $10(47.6 \%)$ & $44(27.2 \%)$ & \\
\hline$>33.9 \mathrm{mg} / \mathrm{mmol}(n, \%)$ & $2(9.5 \%)$ & $7(11.3 \%)$ & \\
\hline Log albumin/creatinine ratio & $1.50 \pm 0.70$ & $1.25 \pm 0.61$ & 0.085 \\
\hline Diabetic Retinopathy $(n, \%)$ & $11(47.82 \%)$ & $40(24.40 \%)$ & 0.018 \\
\hline Diabetic Neuropathy $(n, \%)$ & $3(13.04 \%)$ & $32(19.451)$ & 0.450 \\
\hline CACS > 400 AU $(n, \%)$ & $10(52.63 \%)$ & $31(19.562)$ & 0.001 \\
\hline Log CACs (AU) & $2.55 \pm 0.84$ & $2.05 \pm 0.78 .7$ & 0.013 \\
\hline AGEs 3rd Tertil (AU) & $12(63.15 \%)$ & $39(26.71 \%)$ & 0.001 \\
\hline AAS $(n, \%)$ & $6(27.27 \%)$ & $54(32,92 \%)$ & 0.594 \\
\hline Statines $(n, \%)$ & $14(63.63 \%)$ & $119(72567 \%)$ & 0.384 \\
\hline
\end{tabular}

The multivariate Cox's regression (Table 3), including the selected variables that were significant to the univariate analysis and well-known risk factors of CVD, showed that only age (HR 1.09, 95\% CI 1.01-1.18, $p=0.024$ ), gender (HR 0.35, 95\% CI 0.15-0.83, $p=0.0174$ ), the presence of DR (HR 2.58, 95\% CI 1.14-5.85, $p=0.023$ ), CACS > 400 AU (HR 4.16, 
95\% CI 1.14-10.26, $p=0.002$ ) and a value of SAF on the 3rd tertile (HR 4.68, 95\% CI $1.83-11.96, p=0.001$ ) were independently associated with the presence of a CV event.

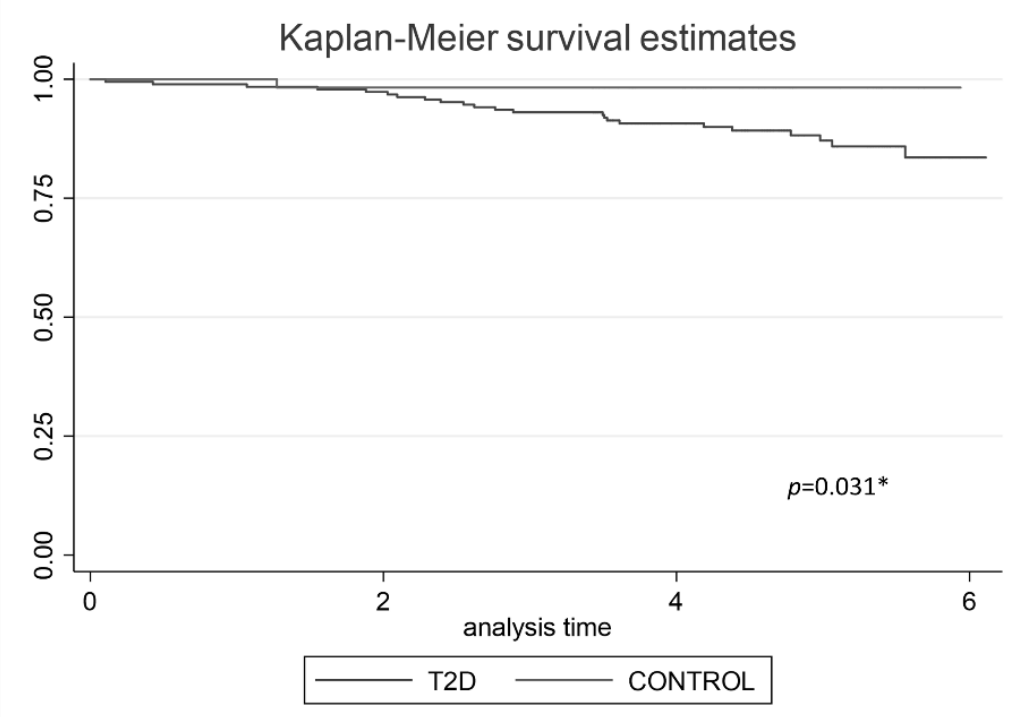

Figure 1. Kaplan-Meier analysis predicting vascular event-free survival regarding groups. * $p$ value $<0.05$ was statistical significative.

Table 3. Results of multivariate Cox's regression for predicting vascular event.

\begin{tabular}{lccc}
\hline & HR & CI 95\% & $p$ \\
\hline Sex (female) & 0.35 & $0.15-0.83$ & 0.017 \\
\hline Age (years) & 1.09 & $1.01-1.18$ & 0.024 \\
\hline BMI $\left(\mathrm{kg} / \mathrm{m}^{2}\right)$ & 0.99 & $0.91-1.08$ & 0.820 \\
\hline Diabetes duration (years) & 1.04 & $0.99-1.08$ & 0.093 \\
\hline Waist $(\mathrm{cm})$ & 1.01 & $0.98-1.04$ & 0.526 \\
\hline Hypertension (yes) & 1.13 & $0.45-2.88$ & 0.792 \\
\hline Dyslipedemia (yes) & 0.59 & $0.24-1.44$ & 0.244 \\
\hline Insulin treatment (yes) & 2.11 & $0.83-5.36$ & 0.116 \\
\hline HbA1c (mmol/mol) & 1.20 & $0.88-1.66$ & 0.255 \\
\hline GFR (mL/min) & 1.02 & $0.99-1.05$ & 0.170 \\
\hline Creatinine (mg/dL) & 0.33 & $0.04-2.44$ & 0.275 \\
\hline Diabetic Retinopathy (yes) & 2.58 & $1.14-5.85$ & 0.023 \\
\hline CACS $>400$ AU (yes) & 4.16 & $1.69-10.26$ & 0.002 \\
\hline AGEs 3rd Tertil (yes) & 4.68 & $1.83-11.96$ & 0.001 \\
\hline
\end{tabular}

\section{Discussion}

In the present study, we confirmed that the individuals with type 2 diabetes had significantly greater risk of having a CV event than the non-diabetic subjects. Furthermore, we provided evidence that DR and SAF (as a measure of tissue-AGE accumulation) were powerful predictors of $\mathrm{CV}$ events in the subjects with type 2 diabetes.

Previously, we provided evidence that DR is an independent predictor of subclinical CVD [19] and that SAF is a good predictor of a CACs > $400 \mathrm{AU}$ (a reliable marker of coronary atherosclerosis) [10]. The current study is important because we confirm that both DR and SAF are not only related to subclinical cardiovascular disease but are also useful in predicting $\mathrm{CV}$ events in type 2 diabetes population. 
According to our findings, previous reports have documented an increase in CV risk in patients with DR, mostly in those with advanced DR [20-22]. Although the underlying molecular mechanisms linking DR and cardiovascular disease are still a matter of debate, there are notable similarities in their pathophysiology. In this regard, recent evidence indicates that in individuals with type 2 diabetes, the vasa vasorum present evolutionary changes similar to those observed in the retina: an initial stage in which endothelial dysfunction and loss of capillaries predominate [16] and more advanced stages in which ischemia plays a key role, leading to angiogenesis and inflammation in response to the progressive enlargement of the necrotic core within the plaque [23]. This change in plaque phenotype results in a more inflamed and unstable plaque, favoring plaque rupture and a poor outcome of cardiovascular events. Thus, microcirculation represents a "common soil" between DR and CV events and would explain why DR is a good predictor of CV events.

To the best of our knowledge, only two previous studies have examined the usefulness of SAF as a predictor of CVD in a prospective way [24,25]. Both support our data and conclude that SAF is strongly associated with the presence of CVD and cardiac mortality. Therefore, SAF could be a useful clinical tool to identify diabetic individuals who have a particularly high risk of developing CV events. It should be noted that our study is the first one conducted in subjects with type 2 diabetes without a history of clinical cardiovascular disease. This is important because it is precisely in this population, before the vascular damage becomes clinically apparent, for which we need useful biomarkers of CV risk.

In our study, we show that higher values of SAF were independently associated with the presence of macrovascular complications. Skin AGEs are accumulated mainly in collagen, which has low turnover and represents hyperglycemia over a longer time period than HbA1c. Therefore, SAF may reflect the impact of oxidative stress and the history of hyperglycemic episodes much better than the classical risk factors. In fact, SAF is considered a measure of metabolic memory in subjects with type 2 diabetes.

In addition to DR and SAF, we found that other classical factors, such as age, male sex and CACs > $400 \mathrm{AU}$, were also related with the presence of a CV event. Age is an important determinant of $\mathrm{CV}$ risk, and it is known that the prevalence of inducible ischemia is significantly higher in type 2 diabetes patients over 65 years old [26]. Furthermore, it is well documented that the absolute risk of $\mathrm{CV}$ events is higher in men than women [27]. CACs is a well-recognized biomarker of myocardial ischemia and a good predictor of $\mathrm{CV}$ events [28]. In fact, guidelines recommend that the assessment of CACs could be considered in asymptomatic patients with diabetes mellitus who are over the age of 40 [3]. However, CACs assessment needs a CT scan examination, which can be inconvenient and rather expensive for routine practice in subjects with type 2 diabetes. For these reasons, retinal photographs, together SAF assessment, could replace CACs as biomarker of $\mathrm{CV}$ risk or, at least, be a useful tool to select those patients in whom CACs should be assessed. Noteworthy is the fact that Rima et al. recently demonstrated that deep learning and a retinal photograph-derived CAC score are comparable to CT scan-measured CAC in predicting a CV event [29].

The main limitation of our study is the low rate of CV events observed. However, it should be noted that there is a clear trend toward a decrease in events in diabetic subjects in the last 20 years, as reported by Rawshani et al. [30]. This is probably due to better management of chronic patients with diabetes, associated with better comprehensive control of the rest of the $\mathrm{CV}$ risk factors through the greater use of statins and antihypertensive drugs.

\section{Conclusions}

In conclusion, this study reconfirms that patients with type 2 diabetes have significantly more $\mathrm{CV}$ events than non-diabetic subjects. In addition, DR and higher values of SAF are powerful predictors of $\mathrm{CV}$ events in subjects with type 2 diabetes and, therefore, might be included as meaningful variables in CV-risk stratification. Furthermore, DR and higher values of SAF could be useful biomarkers in selecting type 2 diabetic patients in 
whom the screening for cardiovascular disease should be prioritized, thereby generating more personalized and cost-effective medicine.

Author Contributions: C.H., I.F.-G. and R.S. conceived the study concept and design, interpreted data and contributed to critically revising the manuscript. A.P., O.S.-S., Á.O.-Z., J.R.M. and J.R.H. collected and analyzed data. A.P. drafted the manuscript. All authors approved the final article. C.H., I.F.-G. and R.S. obtained funding. R.S. is the guarantor of this work and, as such, had full access to all of the data in the study and takes responsibility for the integrity of the data and accuracy of the data analysis. All authors have read and agreed to the published version of the manuscript.

Funding: This research was funded by grants from the Spanish Institute of Health (ISCIII) in the setting of Integrative Excellence Projects (PIE 2013/27) and the European Foundation for the Study of Diabetes (EFSD Pilot Research Grant Programme for Innovative Measurement of Diabetes Outcomes 2017). The study funders were not involved in the design of the study.

Institutional Review Board Statement: The study was conducted according to the guidelines of the Declaration of Helsinki, and was approved by the local ethics committee: Comité Ético de Investigación Clínica del Hospital Universitario de Vall d'Hebron (Ethical Committee for Clinical Research of the Vall d'Hebron University Hospital) with reference number PR(AG)127/2014.

Informed Consent Statement: Informed consent was obtained from all subjects involved in the study.

Data Availability Statement: The data presented in this study are available on request from the corresponding author.

Conflicts of Interest: The authors declare no conflict of interest. The funders had no role in the design of the study; in the collection, analysis or interpretation of data; in the writing of the manuscript; or in the decision to publish the results.

\section{Appendix A}

Appendix A.1. Anthropometric Data, Assessment of the Classic Risk Factors and Laboratory Test

Anthropometric data were obtained by standardized protocols. A balance with a fixed stadiometer was used to measure height and weight. Waist circumstance was measured between the 10th rib and the iliac crest.

The assessment of the classic risk factors was carried out as follows: A history of smoking habits (non-smoker/current smoker/ex-smoker) was recorded. Hypertension was established as systolic blood pressure $\geq 140 \mathrm{~mm} \mathrm{Hg}$ or diastolic blood pressure $\geq 90 \mathrm{~mm} \mathrm{Hg}$ or when subjects were under treatment with antihypertensive agents. Dyslipidemia was defined by the use of lipid-lowering drugs; decreased values of high-density lipoprotein (HDL) cholesterol (men $<0.9 \mathrm{mmol} / \mathrm{L}$, women $<1 \mathrm{mmol} / \mathrm{L}$ ); or at least one increased value of total cholesterol $(>5.2 \mathrm{mmol} / \mathrm{L})$, low-density lipoprotein (LDL) cholesterol $(>4.3 \mathrm{mmol} / \mathrm{L})$ or triglycerides $(>1.7 \mathrm{mmol} / \mathrm{L})$.

Fasting venous blood sample was collected from the antecubital vein, separated by centrifugation $\left(2000 \times g\right.$ at $4{ }^{\circ} \mathrm{C}$ for $20 \mathrm{~min}$ ) and frozen at $-80^{\circ} \mathrm{C}$ for batched storage and analysis. HbA1c was measured using the Cobas B 101 (Roche) system. The remaining biochemical parameters were measured using an Olympus AU5400 automatic biochemistry analyzer (Olympus, Tokyo, Japan).

\section{Appendix A.2. Measurement of Skin Autofluorescence}

The AGE Reader ${ }^{\mathrm{TM}}$ illuminates a skin surface of $4 \mathrm{~cm}^{2}$ guarded against surrounding light and uses an excitation light source with a peak excitation of $370 \mathrm{~nm}$. Subsequently, the emitted fluorescent light (within the wavelength range of 420-600 nm) and the reflected excitation light (within the wavelength range of 300-420 nm) from the skin are measured with a spectrometer. SAF is calculated in arbitrary units (AU) as the ratio between the emitted light and the reflected light, multiplied by 100. A series of three consecutive measurements was carried out, taking less than a minute. The mean SAF was calculated from these three measurements from the ventral side of the forearm. We created a variable according to the SAF value in this population (Higher or Lower SAF): a Higher SAF 
included the 3rd tertile SAF values, while a lower SAF included the 1st and 2nd tertile SAF values.

\section{Appendix B}

Table A1. Diabetes features and comorbidities in type 2 diabetes subjects.

\begin{tabular}{ll}
\hline & $\mathbf{N}=\mathbf{1 8 7}$ \\
\hline Diabetes duration (years) & $14 \pm 9.4$ \\
\hline HbA1c (mmol/mol) & $56.3 \pm 9.01$ \\
\hline HbA1c $(\%)$ & $7.44 \pm 1.19$ \\
\hline Microvascular complications & $50(26.73 \%)$ \\
\hline Retinopathy $(n, \%)$ & $44(23.52 \%)$ \\
\hline Non-proliferative & $23(12.29 \%)$ \\
\hline Mild & $16(8.65 \%)$ \\
\hline Moderate & $5(2.67 \%)$ \\
\hline Severe & $6(3.21 \%)$ \\
\hline Proliferative & \\
\hline Urine albumin/creatinine ratio $(\mathrm{mg} / \mathrm{g})$ & $120(64.52 \%)$ \\
\hline$<3.39$ mg/mmol $(n, \%)$ & $54(29.03 \%)$ \\
\hline $3.39-33.9$ mg/mmol $(n, \%)$ & $9(4.84 \%)$ \\
\hline$>33.9$ mg/mmol $(n, \%)$ & $36(18.37 \%)$ \\
\hline Neuropathy & $82(43.85 \%)$ \\
\hline Diabetes treatment & $105(56.14 \%)$ \\
\hline Oral agents & \\
\hline Insulin \pm Oral agents & \\
\hline
\end{tabular}

\section{References}

1. Stamler, J.; Vaccaro, O.; Neaton, J.D.; Wentworth, D. Diabetes, Other Risk Factors, and 12-Yr Cardiovascular Mortality for Men Screened in the Multiple Risk Factor Intervention Trial. Diabetes Care 1993, 16, 434-444. [CrossRef] [PubMed]

2. American Diabetes Association 9. Cardiovascular Disease and Risk Management: Standards of Medical Care in Diabetes-2018. Diabetes Care 2018, 41, S86-S104. [CrossRef] [PubMed]

3. Fox, C.S.; Golden, S.H.; Anderson, C.; Bray, G.A.; Burke, L.E.; de Boer, I.H.; Deedwania, P.; Eckel, R.H.; Ershow, A.G.; Fradkin, J.; et al. Update on Prevention of Cardiovascular Disease in Adults With Type 2 Diabetes Mellitus in Light of Recent Evidence: A Scientific Statement From the American Heart Association and the American Diabetes Association. Diabetes Care 2015, 38, 1777-1803. [CrossRef] [PubMed]

4. Low Wang, C.C.; Hess, C.N.; Hiatt, W.R.; Goldfine, A.B. Clinical Update: Cardiovascular Disease in Diabetes Mellitus: Atherosclerotic Cardiovascular Disease and Heart Failure in Type 2 Diabetes Mellitus-Mechanisms, Management, and Clinical Considerations. Circulation 2016, 133, 2459-2502. [CrossRef] [PubMed]

5. Schmidt, A.M.; Hasu, M.; Popov, D.; Zhang, J.H.; Chen, J.; Yan, S.D.; Brett, J.; Cao, R.; Kuwabara, K.; Costache, G. Receptor for Advanced Glycation End Products (AGEs) Has a Central Role in Vessel Wall Interactions and Gene Activation in Response to Circulating AGE Proteins. Proc. Natl. Acad. Sci. USA 1994, 91, 8807-8811. [CrossRef] [PubMed]

6. Goldin, A.; Beckman, J.A.; Schmidt, A.M.; Creager, M.A. Advanced Glycation End Products: Sparking the Development of Diabetic Vascular Injury. Circulation 2006, 114, 597-605. [CrossRef]

7. Singh, R.; Barden, A.; Mori, T.; Beilin, L. Advanced Glycation End-Products: A Review. Diabetologia 2001, 44, 129-146. [CrossRef]

8. Meerwaldt, R.; Graaff, R.; Oomen, P.H.N.; Links, T.P.; Jager, J.J.; Alderson, N.L.; Thorpe, S.R.; Baynes, J.W.; Gans, R.O.B.; Smit, A.J. Simple Non-Invasive Assessment of Advanced Glycation Endproduct Accumulation. Diabetologia 2004, 47, 1324-1330. [CrossRef]

9. Bos, D.C.; de Ranitz-Greven, W.L.; de Valk, H.W. Advanced Glycation End Products, Measured as Skin Autofluorescence and Diabetes Complications: A Systematic Review. Diabetes Technol. Ther. 2011, 13, 773-779. [CrossRef]

10. Planas, A.; Simó-Servat, O.; Bañeras, J.; Sánchez, M.; García, E.; Ortiz, Á.M.; Ruiz-Meana, M.; Hernández, C.; Ferreira-González, I.; Simó, R. Usefulness of Skin Advanced Glycation End Products to Predict Coronary Artery Calcium Score in Patients with Type 2 Diabetes. Acta Diabetol. 2021, 58, 1403-1412. [CrossRef] 
11. Simó, R.; Stehouwer, C.D.A.; Avogaro, A. Diabetic Retinopathy: Looking beyond the Eyes. Diabetologia 2020, 63, 1662-1664. [CrossRef]

12. Brownrigg, J.R.W.; Hughes, C.O.; Burleigh, D.; Karthikesalingam, A.; Patterson, B.O.; Holt, P.J.; Thompson, M.M.; de Lusignan, S.; Ray, K.K.; Hinchliffe, R.J. Microvascular Disease and Risk of Cardiovascular Events among Individuals with Type 2 Diabetes: A Population-Level Cohort Study. Lancet Diabetes Endocrinol. 2016, 4, 588-597. [CrossRef]

13. Pearce, I.; Simó, R.; Lövestam-Adrian, M.; Wong, D.T.; Evans, M. Association between Diabetic Eye Disease and Other Complications of Diabetes: Implications for Care. A Systematic Review. Diabetes Obes. Metab. 2019, 21, 467-478. [CrossRef] [PubMed]

14. Xie, J.; Ikram, M.K.; Cotch, M.F.; Klein, B.; Varma, R.; Shaw, J.E.; Klein, R.; Mitchell, P.; Lamoureux, E.L.; Wong, T.Y. Association of Diabetic Macular Edema and Proliferative Diabetic Retinopathy With Cardiovascular Disease: A Systematic Review and Meta-Analysis. JAMA Ophthalmol. 2017, 135, 586-593. [CrossRef] [PubMed]

15. Kurihara, O.; Takano, M.; Mizuno, K.; Shibata, Y.; Matsushita, M.; Komiyama, H.; Yamamoto, M.; Kato, K.; Munakata, R.; Murakami, D.; et al. Impact of Diabetic Retinopathy on Vulnerability of Atherosclerotic Coronary Plaque and Incidence of Acute Coronary Syndrome. Am. J. Cardiol. 2016, 118, 944-949. [CrossRef]

16. Gerstein, H.C.; Nair, V.; Chaube, R.; Stoute, H.; Werstuck, G. Dysglycemia and the Density of the Coronary Vasa Vasorum. Diabetes Care 2019, 42, 980-982. [CrossRef]

17. Wilkinson, C.P.; Ferris, F.L.; Klein, R.E.; Lee, P.P.; Agardh, C.D.; Davis, M.; Dills, D.; Kampik, A.; Pararajasegaram, R.; Verdaguer, J.T.; et al. Proposed International Clinical Diabetic Retinopathy and Diabetic Macular Edema Disease Severity Scales. Ophthalmology 2003, 110, 1677-1682. [CrossRef]

18. American College of Cardiology Foundation Task Force on Expert Consensus Documents; Mark, D.B.; Berman, D.S.; Budoff, M.J.; Carr, J.J.; Gerber, T.C.; Hecht, H.S.; Hlatky, M.A.; Hodgson, J.M.; Lauer, M.S.; et al. ACCF/ACR/AHA/NASCI/SAIP/SCAI/SCCT 2010 Expert Consensus Document on Coronary Computed Tomographic Angiography: A Report of the American College of Cardiology Foundation Task Force on Expert Consensus Documents. J. Am. Coll. Cardiol. 2010, 55, 2663-2699. [CrossRef] [PubMed]

19. Simó, R.; Bañeras, J.; Hernández, C.; Rodríguez-Palomares, J.; Valente, F.; Gutierrez, L.; González-Alujas, T.; Ferreira, I.; Aguadé-Bruix, S.; Montaner, J.; et al. Diabetic Retinopathy as an Independent Predictor of Subclinical Cardiovascular Disease: Baseline Results of the PRECISED Study. BMJ Open Diabetes Res. Care 2019, 7, e000845. [CrossRef]

20. Cheung, N.; Wang, J.J.; Klein, R.; Couper, D.J.; Sharrett, A.R.; Wong, T.Y. Diabetic Retinopathy and the Risk of Coronary Heart Disease: The Atherosclerosis Risk in Communities Study. Diabetes Care 2007, 30, 1742-1746. [CrossRef] [PubMed]

21. Targher, G.; Bertolini, L.; Zenari, L.; Lippi, G.; Pichiri, I.; Zoppini, G.; Muggeo, M.; Arcaro, G. Diabetic Retinopathy Is Associated with an Increased Incidence of Cardiovascular Events in Type 2 Diabetic Patients. Diabet. Med. 2008, 25, 45-50. [CrossRef]

22. Alonso, N.; Traveset, A.; Rubinat, E.; Ortega, E.; Alcubierre, N.; Sanahuja, J.; Hernández, M.; Betriu, A.; Jurjo, C.; Fernández, E.; et al. Type 2 Diabetes-Associated Carotid Plaque Burden Is Increased in Patients with Retinopathy Compared to Those without Retinopathy. Cardiovasc. Diabetol. 2015, 14, 33. [CrossRef]

23. Sedding, D.G.; Boyle, E.C.; Demandt, J.A.F.; Sluimer, J.C.; Dutzmann, J.; Haverich, A.; Bauersachs, J. Vasa Vasorum Angiogenesis: Key Player in the Initiation and Progression of Atherosclerosis and Potential Target for the Treatment of Cardiovascular Disease. Front. Immunol. 2018, 9, 706. [CrossRef]

24. Lutgers, H.L.; Gerrits, E.G.; Graaff, R.; Links, T.P.; Sluiter, W.J.; Gans, R.O.; Bilo, H.J.; Smit, A.J. Skin Autofluorescence Provides Additional Information to the UK Prospective Diabetes Study (UKPDS) Risk Score for the Estimation of Cardiovascular Prognosis in Type 2 Diabetes Mellitus. Diabetologia 2009, 52, 789-797. [CrossRef]

25. Meerwaldt, R.; Lutgers, H.L.; Links, T.P.; Graaff, R.; Baynes, J.W.; Gans, R.O.B.; Smit, A.J. Skin Autofluorescence Is a Strong Predictor of Cardiac Mortality in Diabetes. Diabetes Care 2007, 30, 107-112. [CrossRef] [PubMed]

26. Chaowalit, N.; Arruda, A.L.; McCully, R.B.; Bailey, K.R.; Pellikka, P.A. Dobutamine Stress Echocardiography in Patients with Diabetes Mellitus: Enhanced Prognostic Prediction Using a Simple Risk Score. J. Am. Coll. Cardiol. 2006, 47, 1029-1036. [CrossRef]

27. Abbott, R.D.; Donahue, R.P.; Kannel, W.B.; Wilson, P.W. The Impact of Diabetes on Survival Following Myocardial Infarction in Men vs Women. The Framingham Study. JAMA 1988, 260, 3456-3460. [CrossRef]

28. Elkeles, R.S.; Godsland, I.F.; Feher, M.D.; Rubens, M.B.; Roughton, M.; Nugara, F.; Humphries, S.E.; Richmond, W.; Flather, M.D.; PREDICT Study Group. Coronary Calcium Measurement Improves Prediction of Cardiovascular Events in Asymptomatic Patients with Type 2 Diabetes: The PREDICT Study. Eur. Heart J. 2008, 29, 2244-2251. [CrossRef] [PubMed]

29. Rim, T.H.; Lee, C.J.; Tham, Y.-C.; Cheung, N.; Yu, M.; Lee, G.; Kim, Y.; Ting, D.S.W.; Chong, C.C.Y.; Choi, Y.S.; et al. DeepLearning-Based Cardiovascular Risk Stratification Using Coronary Artery Calcium Scores Predicted from Retinal Photographs. Lancet Digit. Health 2021, 3, e306-e316. [CrossRef]

30. Rawshani, A.; Rawshani, A.; Franzén, S.; Eliasson, B.; Svensson, A.-M.; Miftaraj, M.; McGuire, D.K.; Sattar, N.; Rosengren, A.; Gudbjörnsdottir, S. Mortality and Cardiovascular Disease in Type 1 and Type 2 Diabetes. N. Engl. J. Med. 2017, 376, 1407-1418. [CrossRef] [PubMed] 